\title{
Effectiveness of Isokinetic Exercises in Preoperative Anterior Cruciate Ligament Tears Rehabilitation
}

\author{
${ }^{1}$ Amita Aggarwal, ${ }^{2}$ Bibek Adhya, ${ }^{3}$ Mandeep S Dhillon
}

\begin{abstract}
The present study compared the effectiveness of adding isokinetic exercise program to conventional rehabilitation protocol in preoperated patients with anterior cruciate ligament $(A C L)$ tear. The subjects were randomly assigned into two groups $(n=10$ each). Group A followed conventional rehabilitation protocol. In group $B$, isokinetic exercise for quadriceps and hamstring were advised. These consisted of 3 set of 10 repetitions at velocity of 60 and $120^{\circ} \mathrm{sec}$. with 1 minute rest interval between the sets. The exercise protocol was performed 6 days a week for 4 weeks. Student t-test was used for analysis. Also subjects were evaluated for pain using visual analog scale (VAS). For the assessment of symptoms and functions Cincinnati knee rating system and Lysholm scoring scale were used. The effectiveness of isokinetic exercise was significantly better only with knee extension peak torque and peak work in case of quadriceps $(p<0.05)$. Hamstring testing showed no significant difference with isokinetic training in intragroup as well as intergroup comparison for any measured parameters. Also no significant differences were found with use of functional scales.
\end{abstract}

Conclusion: Isokinetic exercises are effective in improving quadriceps peak torque and peak work in patients with ACL tear.

Keywords: Anterior cruciate ligament tear, Isokinetic exercise, Rehabilitation.

How to cite this article: Aggarwal A, Adhya B, Dhillon MS. Effectiveness of Isokinetic Exercises in Preoperative Anterior Cruciate Ligament Tears Rehabilitation. J Postgrad Med Edu Res 2016;50(1):5-8.

Source of support: Nil

Conflict of interest: None

\section{INTRODUCTION}

Anterior cruciate ligament (ACL) is an important component of knee compartment. It prevents anterior translation of the tibia relative to the femur. It guides the knee into full extension while preventing hyperextension. It also assists in prevention of varus and valgus movements of

\footnotetext{
${ }^{1}$ Assistant Professor, ${ }^{2}$ Physiotherapist, ${ }^{3} \mathrm{Head}$

${ }^{1}$ Department of Physiotherapy, DY Patil College of Physiotherapy Pune, Maharashtra, India

${ }^{2,3}$ Department of Physical Medicine, Postgraduate Institute of Medical Education and Research, Chandigarh, India

Corresponding Author: Amita Aggarwal, Assistant Professor Department of Physiotherapy, DY Patil College of Physiotherapy Pune, Maharashtra, India, Phone: 08308877311, e-mail: amita15_pgi@yahoo.co.in
}

the knee in extension. ${ }^{1}$ Anterior cruciate ligament can be injured in several different ways. By far the most common injury of mechanism involves non-contact injuries, e.g. twisting on a stabilized foot, pivoting or decelerating suddenly while landing from a jump.

It is possible that ACL can be torn with contact involving a valgus force that can produce tear of the ACL, medial collateral ligament (MCL) and, possibly, a detachment of the medial meniscus referred to as 'unhappy triad.' ${ }^{2}$ Many studies support efficacy of nonoperative management in ACL tear cases. Progression to knee instability (anterior translation and rotation) depends on the extent of ACL injury and the activity level of patient. ${ }^{3}$ Conservative treatment of complete ACL tears is not recommended. ${ }^{4}$

Anterior cruciate ligament tear management includes advice on a group of exercises to the patients. This helps in strengthening and restoring function of muscles which get weakened and atrophied as a result of injury. Isotonic and isokinetic exercises are commonly used methods of developing quadriceps muscle strength. ${ }^{5-7}$ Some authors have reported isokinetic strength training to have an upper edge over isotonic training. ${ }^{8,9}$ Isokinetic exercise provides an accommodating resistance at a constant velocity. This theoretically allows for maximal force production at all points throughout the active range of motion (ROM). It also provides an angle-torque curve for each separate muscle action. ${ }^{10}$ Isokinetic assessment of muscle performance is widely used for epidemiological studies, for performance prediction, and for rehabilitation purposes. ${ }^{11,12}$

The study was conducted to estimate the effect of the isokinetic exercises in preoperative ACL tear patients and to compare the efficacy of isokinetic exercises with conventional rehabilitation in such cases.

\section{METHODOLOGY}

Subjects who reported acute ACL injury supported by MRI investigations were recruited from orthopedics and physiotherapy outpatient department (OPD) of PGIMER, Chandigarh. The subjects were provided a 1 month treatment session with specific intervention protocol. The subjects were evaluated for their pain using visual analog scale (VAS). ${ }^{13}$ Cincinnati knee rating system ${ }^{14}$ and Lysholm scoring scale ${ }^{15}$ were used for symptoms and 
functions. Muscles were evaluated using peak torque, work and power as parameters.

Sample size was decided as 20 subjects (10 in each group).

\section{Inclusion Criteria}

Patients aged 20 to 45 years presenting in orthopedics OPD with preoperative, unilateral ACL tear.

\section{Exclusion Criteria}

Subjects with any knee deformities, rheumatic conditions, any previous surgery of involved knee.

\section{Intervention Protocol}

All the recruited patients were randomly assigned to one of the two groups irrespective of sex.

Group A was taken as control. They were given conventional rehabilitation. ${ }^{16}$

Group B was labeled as experimental. They were given conventional rehabilitation along with isokinetic exercises for quadriceps and hamstrings $\left(60^{\circ} \mathrm{s}^{-1}\right.$ and $120^{\circ} \mathrm{s}^{-1}, 30$ repetitions $)^{17}$ using Biodex isokinetic dynamometer (Fig. 1).

The data were analyzed for statistical significance using the Statistical Package for Social Sciences (SPSS 15.0) software.

\section{RESULTS}

In Table 1, the comparison between 1st and 30th day for group A showed significant difference $(\mathrm{p}<0.05)$ in peak torque, peak work and peak power in knee extension.

In Table 2, the comparison between 1st and 30th day for group B showed significant difference $(p<0.05)$ for peak torque, peak work and peak power in knee extension.

In Table 3, the intergroup (Groups A and B) comparison of 30th day data shows significant difference for peak torque and peak work in knee extension $(\mathrm{p}<0.05)$.

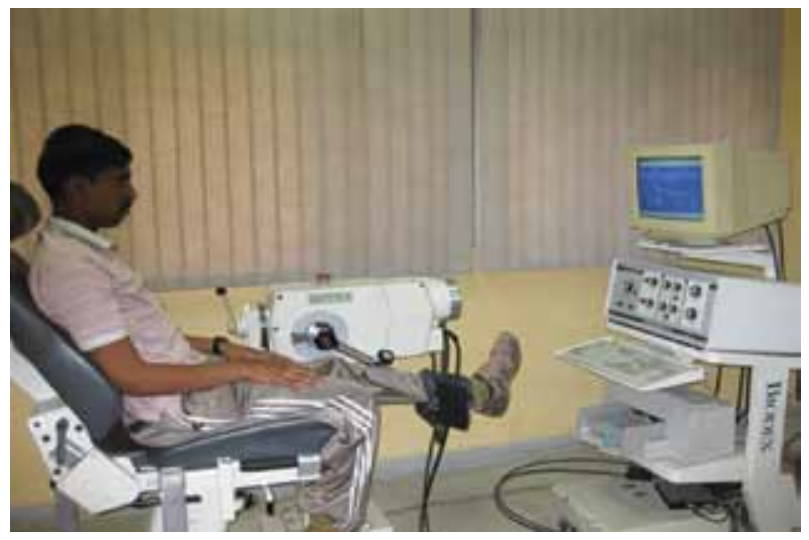

Fig. 1: Patient on isokinetic dynamometer for training
Table $4(n=10)$ shows the comparison between 1st and 30th day scores of Cincinnati knee rating system, Lysholm scoring system and VAS for group A patients.

Table $5(\mathrm{n}=10)$ shows the comparison between 1 st and 30th day for group B.

Table 6 shows intergroup (Groups A and B) comparison of 30th day of both groups.

\section{DISCUSSION}

Pain, effusion and inflammation following ACL tear lead to restricted use of related muscles. ${ }^{18}$ Patients experience inability in fully activating the thigh muscles. This, and

Table 1: Group A comparison on 1st and 30th day of intervention

\begin{tabular}{|c|c|c|c|c|}
\hline Parameters & $\begin{array}{l}\text { Mean } \\
\text { difference }\end{array}$ & $\begin{array}{l}\text { Standard error } \\
\text { of difference }\end{array}$ & $\begin{array}{l}\text { Calculated } \\
\text { t-values }\end{array}$ & $p$-value \\
\hline $\begin{array}{l}\text { Peak torque } \\
\text { extension }\end{array}$ & -27.2360 & 7.704 & 3.5353 & $<0.05$ \\
\hline $\begin{array}{l}\text { Peak torque } \\
\text { flexion }\end{array}$ & 0.1870 & 1.180 & 0.1585 & $>0.05$ \\
\hline $\begin{array}{l}\text { Peak work } \\
\text { extension }\end{array}$ & -15.48600 & 3.6266 & 3.6266 & $<0.05$ \\
\hline $\begin{array}{l}\text { Peak work } \\
\text { flexion }\end{array}$ & 0.59110 & 0.764 & 0.7733 & $>0.05$ \\
\hline $\begin{array}{l}\text { Peak power } \\
\text { extension }\end{array}$ & -4.97370 & 1.753 & 2.8374 & $<0.05$ \\
\hline $\begin{array}{l}\text { Peak power } \\
\text { flexion }\end{array}$ & -0.1530 & 0.095 & 1.6052 & $>0.05$ \\
\hline
\end{tabular}

Table 2: Group B comparison on 1st and 30th day

\begin{tabular}{lllll}
\hline & Mean & \multicolumn{2}{l}{ Standard error } & Calculated \\
Parameters & difference & of difference & t-values & $p$-value \\
\hline $\begin{array}{l}\text { Peak torque } \\
\text { extension }\end{array}$ & -66.0560 & 11.964 & 5.5212 & $<0.05$ \\
$\begin{array}{l}\text { Peak torque } \\
\text { flexion }\end{array}$ & 2.77070 & 1.412 & 1.9629 & $>0.05$ \\
$\begin{array}{l}\text { Peak work } \\
\text { extension }\end{array}$ & -48.87340 & 7.314 & 6.6825 & $<0.05$ \\
$\begin{array}{l}\text { Peak work } \\
\text { flexion }\end{array}$ & -1.27030 & 0.616 & 2.0614 & $>0.05$ \\
$\begin{array}{l}\text { Peak power } \\
\text { extension }\end{array}$ & -20.12640 & 3.820 & 5.2680 & $<0.05$ \\
$\begin{array}{l}\text { Peak power } \\
\text { flexion }\end{array}$ & -0.15540 & 0.205 & 0.7577 & $>0.05$ \\
\hline
\end{tabular}

Table 3: Intergroup (groups A and B) comparisons on 30th day

\begin{tabular}{lrlll}
\hline Parameters & $\begin{array}{l}\text { Mean } \\
\text { difference }\end{array}$ & $\begin{array}{l}\text { Standard error } \\
\text { of difference }\end{array}$ & $\begin{array}{l}\text { Calculated } \\
\text { t-values }\end{array}$ & $p$-value \\
\hline $\begin{array}{l}\text { Peak torque } \\
\text { extension }\end{array}$ & 55.9410 & 23.074 & 2.4244 & $<0.05$ \\
$\begin{array}{l}\text { Peak torque } \\
\text { flexion }\end{array}$ & -0.52370 & 1.734 & 0.3021 & $>0.05$ \\
$\begin{array}{l}\text { Peak work } \\
\text { extension }\end{array}$ & 39.35730 & 14.407 & 2.7319 & $<0.05$ \\
$\begin{array}{l}\text { Peak work } \\
\text { flexion }\end{array}$ & 0.99300 & 0.602 & 1.6508 & $>0.05$ \\
$\begin{array}{l}\text { Peak power } \\
\text { extension }\end{array}$ & 14.8800 & 7.439 & 2.0002 & $>0.05$ \\
$\begin{array}{l}\text { Peak power } \\
\text { flexion }\end{array}$ & 0.07160 & 0.165 & 0.4347 & $>0.05$ \\
\hline
\end{tabular}


Table 4: Comparison of control group (group A) scores on 1 st and 30th day

\begin{tabular}{lllll}
\hline Scales & \multicolumn{2}{l}{ Mean difference } & Standard error & Calculated \\
in scores & of difference & t-values & $p$-value \\
\hline $\begin{array}{l}\text { Cincinnati } \\
\text { scale }\end{array}$ & 2.565 & 4.2890 & $<0.05$ \\
$\begin{array}{l}\text { Lysholm } \\
\text { scale }\end{array}$ & -11.70 & 2.887 & 4.0527 & $<0.05$ \\
VAS & 9 & 0.249 & 4.8107 & $<0.05$ \\
\hline
\end{tabular}

Table 5: Comparison of group B scales scoring on 1st and 30th day

\begin{tabular}{|c|c|c|c|c|}
\hline Scales & $\begin{array}{l}\text { Mean difference } \\
\text { in scores }\end{array}$ & $\begin{array}{l}\text { Standard error } \\
\text { of difference }\end{array}$ & $\begin{array}{l}\text { Calculated } \\
t \text {-values }\end{array}$ & $p$-value \\
\hline $\begin{array}{l}\text { Cincinnati } \\
\text { scale }\end{array}$ & -14.10 & 2.618 & 5.3856 & $<0.05$ \\
\hline $\begin{array}{l}\text { Lysholm } \\
\text { scale }\end{array}$ & -15.80 & 4.245 & 3.7223 & $<0.05$ \\
\hline VAS & 2.50 & 0.401 & 6.2284 & $<0.05$ \\
\hline
\end{tabular}

Table 6: Intergroup (groups A and B) comparisons on 30th day

\begin{tabular}{|c|c|c|c|c|}
\hline Scales & $\begin{array}{l}\text { Mean difference } \\
\text { in scores }\end{array}$ & $\begin{array}{l}\text { Standard error } \\
\text { of difference }\end{array}$ & $\begin{array}{l}\text { Calculated } \\
\text { t-values }\end{array}$ & $p$-value \\
\hline $\begin{array}{l}\text { Cincinnati } \\
\text { scale }\end{array}$ & 2.50 & 7.828 & 0.3194 & $>0.05$ \\
\hline $\begin{array}{l}\text { Lysholm } \\
\text { scale }\end{array}$ & 4.60 & 6.884 & 0.6682 & $>0.05$ \\
\hline VAS & -0.40 & 0.678 & 0.5898 & $>0.05$ \\
\hline
\end{tabular}

disuse of the knee musculature, results in muscle atrophy (wasting). All this can lead to knee joint instability in such patients.

Experts have opined that regaining muscular control is essential if the affected individuals want to return to pre-injury level of function. ${ }^{19,20}$ Computerized tomographic studies of cross-sectional areas of affected thigh muscles have demonstrated that atrophy of muscle tissue was greater in the quadriceps femoris muscle than in the hamstring muscles after ACL injury. ${ }^{21,22}$ Studies of thigh muscles strength have also shown that muscle strength deficits were greater in the quadriceps femoris muscle. ${ }^{23,24}$ Kannus ${ }^{25}$ in 1988 had investigated peak torque and total work ratio of hamstring to quadriceps in 41 subjects with ACL insufficient knee. He found high hamstring to quadriceps ratios at higher isokinetic speed $\left(180^{\circ}\right.$ sec.) for both variables. The reason attributed was weak quadriceps femoris. These studies support our findings of recovery of quadriceps muscle strength after exercise protocols which were very specific in both groups. As hamstring muscle power was not much affected after injury, so, there were no significant differences at the end of 30th day in the two groups. However, the muscle power improved due to strengthening exercises and proprioception training.

Our study showed that the strengthening program and proprioception training were beneficial as also documented by Trees et al (2005). ${ }^{1}$ Also, the study by Lorme $(1945)^{26}$ supported the benefits of exercises for the strength gain. Kannus (1988) ${ }^{25}$ also used various exercises in case of post injury anterior cruciate ligament rehabilitation.

The improvement in knee extensors (quadriceps) was also noted in this study as a result of strengthening exercises. These improve the muscle power by increasing the size of the muscle fibers. Exercise also maximize the ventilatory oxygen uptake by increasing both maximum cardiac output (the volume of blood ejected by the heart per minute determines the amount of blood delivered to the exercising muscles). It also affects the ability of muscles to extract and use oxygen from blood. ${ }^{27}$

Closed and open kinetic chain exercises activate muscular patterns and restore proprioception. ${ }^{16}$ So, this was also a factor which improved the muscle strength as observed in this study. Sulejman et al (1998) ${ }^{28}$ documented that under constant specified speed of movement the isokinetic exercises resulted in better functional and structural adaptations.

Force-velocity and power-velocity curvilinear relationships reported in the literature explain the significance of muscle training at particular speeds. ${ }^{29,30}$ The potential to produce power is greatest when muscles are exercised at faster speeds. Force production is greatest when these are exercised at slower speeds. Slower speed exercises are performed under greater resistance than those at faster speeds when the muscle may fatigue more quickly. Also Kovaleski (1992) ${ }^{5}$ documented that the fast speed isokinetic training had a greater potential to develop the muscle strength. But patients with ACL tear have unstable knees. So, the fast speed isokinetic training protocol is not possible. Our significant results obtained with use of knee extensors peak torque and work being performed at slow speed $\left(60^{\circ}\right.$ sec.) concur with this notion.

$\mathrm{Li}(1996)^{17}$ documented that isokinetic concentric strength measured by dynamometry is more reliable than the measures of eccentric strength. This may possibly result in inhibition of maximum contraction in individuals unaccustomed to these exercises. Present study used only concentric exercise. In fact, it is impractical to advocate eccentric isokinetic exercise with dynamometer in preoperative ACL rehabilitation.

A significant intragroup improvement related to function and symptom was seen in the subjects. But, the tools used by us (Cincinnati knee rating system, Lysholm scoring system and VAS) were also unable to find out a significant difference or an edge of isokinetic training over the control group. In a study by Schmitz and Westwood $(2001)^{31}$ isotonic training was found to be more efficacious than isokinetic exercises. This is possibly because greater motor unit activation per unit of work can be performed 
with isotonic exercises. Other studies ${ }^{8,32}$ also found that strength changes with isokinetic training. But, this does not correlate with any changes in functional task performed.

The study had some limitations. The sample size was small. Also, high speed isokinetic training and eccentric isokinetic training were not possible with ACL tear patients.

\section{CONCLUSION}

Isokinetic training resulted in improvement of the muscle strength surrounding knee in cases of ACL tear. There was improvement in quadriceps muscle in both the groups with exercises for all measured parameters in knee extension. Intergroup comparison was found statistically significant only with isokinetic knee extension peak torque and peak work.

\section{REFERENCES}

1. Trees AH, Howe TE, Dixon J, White L. Exercise for treating isolated anterior cruciate ligament injuries in adults (Review). Cochrane Database of Systematic Reviews 2005;4(1):1-41.

2. O'Donoghue D. Surgical treatment of fresh injuries to the major ligaments of the knee. J Bone Joint Surg Am 1950;32(4): 721-738.

3. De Franco MJ, Bach BR. A comprehensive review of partial anterior cruciate ligament tears. J Bone Joint Surg Am 2009; 91(1):198-208.

4. Kannus P, Jarvinen M. Conservatively treated tears of the anterior cruciate ligament: long-term results. J Bone Joint Surg Am 1987;69(7):1007-1012.

5. Kovaleski JE, Heitman RJ, Scaffadi FM, Fondren FB. Effects of isokinetic velocity spectrum exercise on average power and total work. J Athlet Train 1992;27(1):54-56.

6. Colak S, Djurdjevic S, Rudnjanin S. Isokinetic muscle training of pilots of combat aviation. Facta Universitatis series. Physical Education 1998;1(5):29-32.

7. Gerberich SG, Erickson D, Serfass R, Beard B, Poulson E, Ross S, Scott PW, Dauwalter T, Olsen C, Lewis S. Quadriceps strength training using two forms of bilateral exercise. Arch Phy Med Rehabil 1989;70(10):775-779.

8. Cordova ML, Ingersoll CD, Kovaleski JE, Knight KL. A comparison of isokinetic and isotonic predictions of a functional task. J Athlet Train 1995;30(4):319-322.

9. Wojtys EM, Huston LJ, Taylor PD, Bastian SD. Neuromuscular adaptations in isotonic, isokinetic and agility training programs. Am J Sports Med 1996;24(2):187-192.

10. Purkayastha S. Surface electromyographic amplitude-to-work ratios during isokinetic and isotonic muscle actions. J Athletic Training 2006;41(3):314-320.

11. Moffroid M, Whipple R, Hofkosh J, Lowman E, Thistle H. A study of isokinetic exercise. Phys Ther 1969;49(7):735-747.

12. Thistle HG, Hislop HJ, Moffroid M, Lowman EW. Isokinetic contraction: a new concept of resistive exercise. Arch Phys Med Rehabil 1967;48(6):279-282.

13. Wewers ME, Lowe NK. A critical review of visual analogue scales in the measurement of clinical phenomena. Res Nurs Health 1990;13:227-236.
14. Noyes FR, McGinniss GH, Mooar LA. Functional disability in the anterior cruciate insufficient knee syndrome. Sports Med 1984;1(4):287-288.

15. Lysholm J, Gillquist J. Evaluation of knee ligament surgery results with special emphasis on use of a scoring scale. Am J Sports Med 1982;10(3):150-154.

16. WilkKE,Christopher A, Andrew JR, Clancy WG. Rehabilitation after anterior cruciate ligament reconstruction in the female athlete. J Athlet Train 1999;34(2):177-193.

17. Li RC, Wu Y, Maffulli N, Chan K M, Chan JL. Eccentric and concentric isokinetic knee flexion and extension: a reliability study using the Cybex 6000 dynamometer. Br J Sports Med 1996;30(2):156-160.

18. Synder-Mackler L, De Luca PF, Williams PR, Eastlack ME, Bartolozzi AR 3rd. Reflex inhibition of the quadriceps femoris muscle after injury or reconstruction of the anterior cruciate ligament. J Bone Joint Surg-Am 1994;76(4):555-560.

19. Henriksson M, Ledin T, Good L. Postural control after anterior cruciate ligament reconstruction and functional rehabilitation. Am J Sports Med 2001;29(3):359-366.

20. Mattacola CG, Perrin DH, Gansneder BM, Gieck JH, Saliba EN, McCue FC. Strength, functional outcome, and postural stability after anterior cruciate ligament reconstruction. J Athlet Train 2002;37(3):262-268.

21. Gerber $\mathrm{C}$, Hoppeler $\mathrm{H}$, Claassen $\mathrm{H}$, et al. The lower extremity musculature in chronic symptomatic instability of the anterior cruciate ligament. J Bone Joint Surg Am 1985;67(7):1034-1043.

22. Ingemann-Hansen $\mathrm{T}$, Halkjaer-Kristensen J. Computerized tomographic determination of human thigh components: the effects of immobilization in plaster and subsequent physical training. Scand J Rehabil Med 1980;12(1):27-31.

23. Ardvidsson I, Eriksson E, Häggmark T, et al. Isokinetic thigh muscle strength after ligament reconstruction in the knee joint. Int J Sports Med 1981;2(1):7-11.

24. Kannus P, Latvala K, Järvinen M. Thigh muscle strengths in the anterior cruciate ligament deficient knee. J Orthopaed Sports Physical Therap 1987;9(6):223-227.

25. Kannus P. Ratio of hamstring to quadriceps femoris muscles strength in the anterior cruciate ligament insufficient knee. Physical Therapy 1988;68(6):961-965.

26. De Lorme T. Restoration of muscle power by heavy resistance exercises. J Bone Joint Surg Am 1945;27(4):645-667.

27. Fletcher GF, Balady G, Blair SN, Blumenthal J, Caspersen C, Chaitman B, Epstein S, Froelicher ESS, Froelicher VF, Pina IL, et al. Statement on exercise: benefits and recommendations for physical activity programs for all Americans. Circulation 1996;94(4):857-862.

28. ColakS, Djurdjevic S, Rudnjanin S. Isokinetic muscular training of pilots of combat aviation. Physical Education 1998;1(5): 29-32.

29. Hill AV. The maximum work and mechanical efficiency of human muscles, and their most economical speed. J Physiol Lond 1922;56(1-2):19-41.

30. Komi PV. Neuromuscular performance: factors influencing force and speed production. Scand J Sports Sci 1979;1(1):2-15.

31. Schmitz RJ, Westwood KC. Knee extensor electromyographic activity-to-work ratio is greater with isotonic than isokinetic contractions. J Athlet Train 2001;36(4):384-387.

32. Wawrzyniak JR, Tracy JE, Storrow RR. Effect of closed chain exercise on quadriceps femoris peak torque and functional performance. J Athlet Train 1996;31(4):335-340. 